\title{
Effects of Climate Change in Agricultural Insect Pest
}

\author{
Saroj Shrestha* \\ Department of Agriculture, Agriculture and Forestry University, Nepal \\ *Corresponding Author: Saroj Shrestha, Department of Agriculture, Agriculture and Forestry University, Nepal.
}

Received: October 16, 2019; Published: November 19, 2019

DOI: 10.31080/ASAG.2019.03.0727

\begin{abstract}
Climate change, an emerging global concern have serious effects in every aspects of agriculture. Changed patterns in climatic factors like temperature, precipitation, humidity and other meteorological components are affecting the quality and quantity of agricultural commodities production. Along with direct impacts in crop productivity, climate change is threatening global food production via pest related losses of food crops. Each additional degree of temperature rise could cause yield losses from insect pests to increase by a further $10-25 \%$. Climate change has increased pest population and their damage potential by expanding distribution, enhancing survivability and allowing to develop the adaptability of insect pest. Rising temperature, modified precipitation patterns, disturbed gaseous composition of atmosphere etc. are causing the change in population, mobility, behavior of insect pest. This change has been affecting the global agricultural production figure. Largest grain producers of the world viz. China, the US, France etc. are already facing massive infestation of crop pest and consequent yield losses.

Keywords: Agriculture; Carbon Dioxide; Distribution; Temperature; Rainfall
\end{abstract}

\section{Introduction}

Climate change has been the talk of the century. Observed shifts in global climatic phenomena and consequent losses have caught the attention of the world. Climate Change can be illustrated as the phenomenon that includes change in environmental factors like temperature, humidity and precipitation over long period of time. Due to increased temperature, elevated $\mathrm{CO} 2$ and other harmful gases, irregular rainfall, global food production is under the threat. Global temperature has been steadily rising since 1900 with an increase of about $1^{\circ} \mathrm{C}$ since then. A variety of numerical models representing the physical processes in the atmosphere, ocean, cryosphere and land surface simulate the response of the global climate systems to increasing greenhouse gas concentrations and forecast how the climate is expected to change until 2050 and 2070.

Effects of climate change can be observed in multiple ways. The assessment of climatic factors like temperature, precipitation (amount, frequency and timing), humidity, wind (velocity, timing), gaseous concentration etc. can provide real insights of climate change. As well as the examination of consequent effects of modification of these factors can also act as indicator of climate change. As the complexity of climate variables have direct concern in agriculture, the major impacts on agriculture is inevitable.

As in agriculture, climate change can intervene in normal plant physiologies like photosynthesis, respiration, transpiration, nutrient uptake, mineral balance, ionic exchange etc. As well as, climate change can interfere crop production via modification of population and function of pests and pathogens. Climate variables like temperature, humidity, precipitation etc. are the factors for the growth, development and multiplication of creatures like insects, fungi, bacteria, virus etc., pest population is also expected to change as with the change in the climate. Along with this, climate change is expected to bring changes in host plant resistance against diseases and pests. The resistance can be overcome by quicker disease cycles and modified physiologies of insect pest.

Changing climate variables can either increase or decrease the pest population. Species which can overcome the extremities of climate and adapt in the changed atmosphere can maintain its population and consequently devour crop vegetation. In comparison to the insect species found in tropical and temperate regions, shifting temperature have significant effects on species found in temperate region. Altitudinal shift and intrusion in higher altitudes by insect pests have been evident in temperate regions of the world. This has brought new challenges for sustainability of agriculture.

\section{Materials and Methods}

This review paper is based on researches, journals and articles available online and offline. Papers and books from international research and observations related to climate change and their consequences on agriculture particularly via insect pests are made as basis for reviewing. Datas from international journals, magazines, documentaries etc. have been used for the paper. Booklets, brochures, projects results, programs, videos etc. have been used as the secondary source of information.

Browsing, collecting, observing, scanning and sorting out of datas were done to make the paper complete and comprehensive. For making the paper more conclusive, many professors, entomologists, climate change activists were asked with concerned information on the topic. 


\section{Discussion}

For species to survive in the changing climates, they must either adapt in situ to new conditions or shift their distributions in pursuit of more favorable ones. Many insects have large population sizes and short generation times, and their phenology, fecundity, survival, selection and habitat use can respond rapidly to the climate change. These changes to insect life-history may in turn produce rapid changes in their abundance and distribution. Abundancy of insect pest will be enhanced by increased temperature and almost every species of insect are affected by changing temperature [1]. In-season effects of warming include the potential for increased levels of feeding and growth, including the possibility of additional generations in a given year [2]. This has serious impacts on crop growth and also in the pest management scheme. Increased global temperature will also influence the phenology of insects including early arrival of insect pests in their agricultural habitats and emergence time of a range of insect pests [3]. Climate change causes:

1. Changes in diversity and abundance of insect pests

2. Changes in geographical distribution of insect pests

3. Increased overwintering insects

4. Rapid population growth and no. of generations

5. Introduction of alternative hosts plants

6. Changes in host plant resistance

7. Increased risk of invasive pest species

8. Emergence and dissemination of insect transmitted diseases

All these impacts have ultimate effects on agriculture and food security and have put forward new challenges for pest management. Long-term monitoring of population levels and insect behavior, particularly in identifiably sensitive regions, may provide some of the first indications of a biological response to climate change.

\section{Impacts of rising temperature}

Temperature can affect the insect species in several complex ways. As insects are poikilothermic, their growth, development and multiplication is dominantly affected by temperature. That's why, change in temperature is obvious to change insect dynamics. Species which cannot adapt and thrive in increased temperature tend to have hard times maintaining its population while others may thrive and multiply rapidly. Temperature have roles in metabolism, metamorphosis, mobility, host availability etc. which determines the possibility of change in insect pest population and dynamics.

\section{Increase in pest population}

Researchers have shown that increased temperatures can potentially affect insect survival, development, geographic range, and population size. Depending on the development strategy of an insect species, temperature can exert different effects [1]. Temperature can impact insect physiology and development directly or indirectly through the physiology or existence of hosts. Insects which take several longer period to complete one life cycle will tend to moderate temperature variability over the course of their life history. Some crop pests are "stop and go" developers in relation to temperature - they develop more rapidly during periods of time with suitable temperatures. With every degree rise in global temperature, the life cycle of insect will be shorter. The quicker the life cycle, the higher will be the population of pests. In temperate regions, most insects have their growth period during the warmer part of the year because of which, species whose niche space is defined by climatic regime, will respond more predictably to climate change while those in which the niche is limited by other abiotic or biotic factors will be less predictable [1]. The general prediction is that if global temperatures increase, the species will shift their geographical ranges closer to the poles or to higher elevations and increase their population size $[1,4,5]$. We often use degree-day or phenology based models to predict the emergence of these insects and their potential to damage crops (cabbage maggot, onion maggot, European corn borer, Colorado potato beetle). Increased temperatures will accelerate the development of these types of insects - possibly resulting in more generations (and crop damage) per year. It has been estimated that with a $2^{\circ} \mathrm{C}$ temperature increase insects might experience one to five additional life cycles per season $[6]$.

Temperature may change gender ratios of some pest species such as thrips [7] potentially affecting reproduction rates. Lower winter mortality of insects due to warmer winter temperatures could be important in increasing insect populations [4].

Natural enemy and host insect populations may respond differently to changes in temperature. Parasitism could be reduced if host populations emerge and pass through vulnerable life stages before parasitoids emerge. Reduction in vulnerable window can enhance

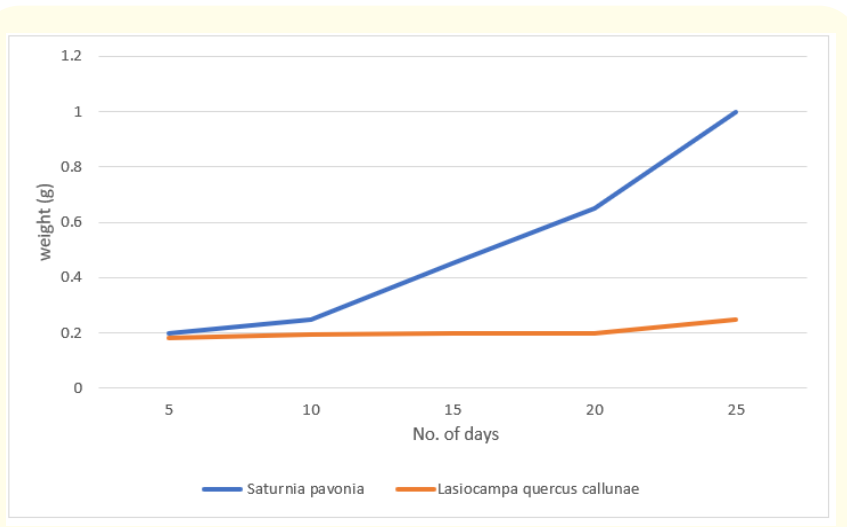

Figure 1: Growth rate curves for Saturnia pavonia and Lasiocampa quercus callunae feeding on Calluna sp. at $20^{\circ} \mathrm{C}$ in mid summer (July). The species with an annual life cycle, S. pavonia, exhibits an exponential increase in size over a period of 25 days in comparison with the almost negligible increase in size displayed by L. quercus callunae, a species with a longer biennial life cycle. Saturnia pavonia will develop quicker and will be probably more responsive to climate warming through changing its distribution. Lasiocampa quercus callunae has a shallow growth curve and will take longer to develop and so will be restricted in its response to climate change.

(Source: (Bale et al., 2002)) 
the pest population. Insects that spend important parts of their life histories in the soil may be more gradually affected by temperature changes than those that are above ground simply because soil provides an insulating medium that will tend to buffer temperature changes more than the air [1]. Insect species diversity per area tends to decrease with higher latitude and altitude [8,9], meaning that rising temperatures could result in more insect species attacking more hosts in temperate climates [1]. Bale., et al. [1] concluded that the diversity of insect species and the intensity of their feeding have increased historically with increasing temperature based on archeological findings of some researchers.

\section{Decrease in pest population}

Not all the insect pest can survive and adapt in the changing climate. Climate change can challenge the availability for their food, mobility, space for oviposition, sex expression etc. As well as, climate change implies the change in vegetation richness in the environment. It may imply the decrease in host population, causing insect pest to suffer from lack of hosts for food, oviposition etc.

From agricultural point of view, farmers may not grow the same species of crop if experiences uneconomical consequences from the crop. This causes the lesser possibility of pest to thrive and multiply. At higher temperatures, aphids have been shown to be less responsive to the aphid alarm pheromone they release when under attack by insect predators and parasitoids - resulting in the potential for greater predation [10].

\section{Change in insect pest diversity and distribution}

Insects comprise the largest group of animal kingdom and play vital role in providing various ecosystem services $[11,12]$. Insects are very good indicators of climate status. The insect diversity in a habitat indicates the health status of an ecosystem as they are very good indicators of environmental change (Gregory et al., 2009), play an important role in food chains. The climate change may affect the relative abundance of different insect species and the species unable to adapt the changes may be lost in the due course of time [13]. There is a need to increase functional diversity in agroecosystems vulnerable to climate change to improve system resilience, and decrease the extent of losses due to insect pests. Climate change can cause decreased activity of decomposers and predators and increased herbivory which can cause serious impacts on agriculture. Climate change is liable to habitat fragmentation resulting creation of smaller subunits of species. Such fragmentation changes the microenvironment at the fragmented edges and edges effects include microclimate, changes in light, temperature and humidity and each of these can have a significant impact on the vitality and composition of the species in the fragment.

For pest species in general, there is a common prediction of pole ward shifts in distributional limits in relation to climate change [14]. It is projected to shift in the species ranges to higher altitudes and increases in the number of generations of pests in central Europe by 2055 . However, in southern Europe, the number of gen- erations was expected to decrease due to temperature increases that would negatively affect pest populations. This implies climate change acts differently on different species. Importantly, the aggregate response of multiple pest species may be different to species-specific responses for instance at the regional level, which can show contrasting or masked patterns to overall trends [15].

\section{Geographical range expansion}

The distribution of insect depends upon the interaction of insects on climatic variables meaning insects are specifically bound to certain climate parameters. Changing climate also implies the expansion of climate zone suitable for certain species. It is predicted that a $1^{\circ} \mathrm{C}$ rise in temperature would enable speed $200 \mathrm{~km}$ northwards (in northern hemisphere) or $40 \mathrm{~m}$ upward (in altitude). Previously unsuitable areas may favor the existence of newer pests. Minimum temperature rather than maximum temperature plays an important role in determining the global distribution of insect species, hence any increase in temperature will result in a greater ability to overwinter at higher altitudes, ultimately causing a shift of pest intensity from south to north. As many insect pest's abundance is directly determined by the temperature rather than vegetation, increasing temperature can result in increase in range of pest abundance. Researches have shown that with rise in temperature, the insect-pests are expected to extend their geographic range from tropics and subtropics to temperate regions at higher altitudes along with shifts in cultivation areas of their host plants. Mostly polar region are constrained from the insect outbreaks due to low temperature and frequently occurring frosts. In future, projected climate warming [16] and increased drought incidence [17] is expected to cause more frequent insect outbreaks in temperate regions also. Global warming results altitude wise range expansion and increased overwintering survival of corn earworms Heliothis zea and Helicoverpa armigera may cause heavy yield loss and put forth major challenge for pest management in maize. Range extension in migratory species like Helicoverpa armigera (Hubner), a major pest of cotton, pulses and vegetables in North India is predicted with global climate warming.

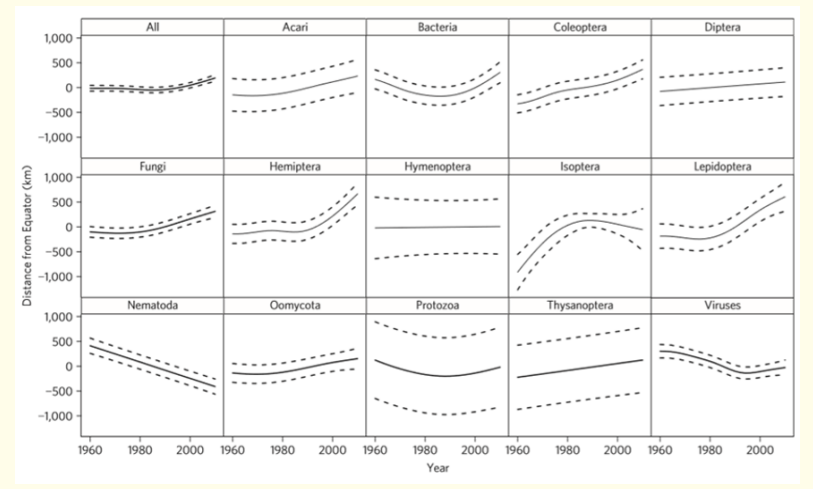

Figure 2: Latitude versus year of observation for pest taxonomic groups in the Northern Hemisphere from 1960 onwards. Fits for all pests combine dare shown for comparison. Fitted values (solid line) and standard errors (dashed lines) are derived from generalized additive mixed models. (Bebber et al., 2013). 
Changes in insect phenology

Change in insect phenology is the most observed indicator of climate change. It is easier to assess climate change by analyzing the change in phenology of insect. With increased temperatures, it is expected that insects will pass through their larval stages faster and become adults earlier. Expected responses in insects could include an advance in the timing of larval and adult emergence and an increase in the length of the flight period [18]. Early adult emergence and an early arrival of migratory species have also been reported for aphids. Gordo Sanz [19] investigated climate impacts on four Mediterranean insect species viz. butterfly, bee, fly and beetle and indicated that all species exhibited changes in their first appearance date over the last 50 years, which was correlated with increases in spring temperature. The timing of arrival of insect species can also be recorded through light traps, suction traps or pheromone traps. Analysis of long-term data on phenology would reveal changes in the timings of pest appearance under the climate change [20]. Analysis of suction trap data has revealed that spring flights of the potato aphid Myzus persicae started two weeks earlier for every $1^{\circ} \mathrm{C}$ rise in combined mean temperature of January and February. Long-term data from several insect-recording schemes in Europe and North America have provided evidence for species becoming active, migrating or reproducing earlier in the year due to increases in temperatures that lead directly to increased growth rates or earlier emergence from winter inactivity [21].

\section{Change in diapause duration}

Insects have evolved through various behavioral strategies like diapause to survive in stressed environment. Diapause is affected by factors like temperature, humidity, photoperiod etc. Maintenance of population of insect pest is favored by adaptive traits like diapause. Diapause plays vital role in seasonal regulation of insect life cycles because of which the insects have better advantage to survive great deal of environmental adversities. Aestivation and hibernation are two types of diapauses. Aestivation enables insects to survive in higher temperature while hibernation in lower temperature.

Higher temperature implies accelerated metabolic activities in insects resulting shortening of duration of diapauses (mainly hibernation). This means the activity period of insect is extended making them active during longer period of time. This gives an important implication that increase in temperature in the range of $1^{\circ} \mathrm{C}$ to $5^{\circ} \mathrm{C}$ would increase insect survival due to low winter mortality, increased population built-up, early infestations and resultant crop damage by insect-pests under global warming scenario [4].

\section{Invasion by alien species}

Climate change can also provide conducing environment for alien species to be established. Along with other facets for the arrival and establishment of exotic species, climate change plays a vital role. Major reason besides climate change is globalization of world trade which prevents the restriction on global trade. According to

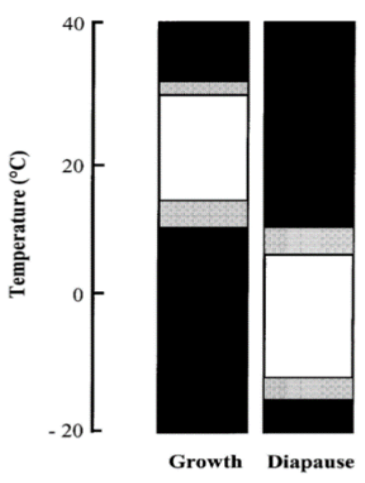

Figure 3: Temperature requirements for growth and diapause in Saturnia pavonia. Favorable temperature ranges are shown by the white bars, lethal temperature ranges are shown by the black bars, and depressing temperature ranges are shown by the grey bars. There is a restricted 'window' for growth (white bar), with an upper and lower threshold beyond which development does not occur. To prevent imminent death when temperatures drop below c. $5{ }^{\circ} \mathrm{C}$, S. pavonia enters diapause; however, death follows if the temperature continues to drop. (Bebber et al., 2013).

the Convention on Biological Diversity (CBD), invasive alien species are the greatest threat to loss of biodiversity in the world and impose high costs to agriculture, forestry and aquatic ecosystems by altering their regional structure, diversity and functioning. In Nepal, Tuta absoluta was introduced in 2016. Now, it has been the major pest of tomato in the country [22].

\section{Pest outbreaks}

It is the result of complex condition created by multiple factors like increased metabolism, modified voltinism, host plant availability etc. It may result in upsetting ecological balance because of unpredictable changes in the population of insect-pests along with their existing and potential natural enemies. Outbreak of sugarcane woolly aphid Ceratovacuna lanigera Zehntner in sugarcane belt of Karnataka and Maharashtra states during 2002-03 resulted in $30 \%$ yield losses. Pest outbreak has caused serious challenge in the agriculture especially for the small holding farmers [23].

\section{Insects as vectors of diseases}

Some insect species contributes to crop losses by transmitting pathogens. Mainly hemipteran insects are responsible for transmitting diseases. Climate change may lead to more incidence of insect transmitted plant diseases through range expansion and rapid multiplication of insect vectors [24]. Increase in the population and hazards of insects like aphids can be implied as the increase transmission of related diseases.

\section{Increased level of carbon dioxide}

Carbon dioxide is a notorious gas always associated with climate change. Increased level of $\mathrm{CO}_{2}$ has always been the subject of study in climate change. Carbon dioxide involves in increasing insect population increment by intervening the plant nutritional 
composition. Plants consist primarily of carbon and elevated $\mathrm{CO}_{2}$ levels allow them to grow more rapidly because they can assimilate carbon more quickly. Increase in carbon dioxide is often understood as increase in photosynthetic rate and is believed that plant attains better drought tolerance in higher $\mathrm{CO}_{2}$ concentration. This allows the situation where the availability of host is ensured for insects even in harsh conditions. Consequently, it induces the conditions where pest incidence in abundant.

More importantly, major reason for increased level of damage in higher $\mathrm{CO}_{2}$ level is the decreased nutrient level in plants. Plants exposed to higher carbon dioxide implies lower level of nitrogen resulting poor nutrient content in host plants. A rise in $\mathrm{CO}_{2}$ in atmosphere generally increases the carbon to nitrogen ratio due to accumulation of non- structural carbohydrates of plant tissues thereby reducing the nutritional quality for protein limited insects diluting the nitrogen content by $15-25 \%$ in the tissues [25]. So, in order to compensate the nitrogen requirement of insects, the feed intake of insects grows rapidly. A higher level of sugars like glucose, sucrose, and fructose in soybean foliages grown under higher $\mathrm{CO}_{2}$ is considered to be a preferential factor for Japanese beetle, $P$. japonica. It has also been reported that increased level of carbon dioxide has been related with higher fecundity of aphids. When reared in higher $\mathrm{CO}_{2}$ concentration, some insects like pine sawfly has shown increased level of efficiency in nitrogen utilization [26]. Impacts of climate change in insect population has been studied through OTC (Open Top Chambers) and free air carbon dioxide enrichment (FACE).

OTCs modify the environment by altering light intensity, relative humidity, wind speed and direction, and other environmental factors. Rao., et al. [27] conducted feeding trials with two insect species, A. janata and S. litura. Foliage of castor plants were given to feed along with three concentrations of $\mathrm{CO}_{2}$ viz., $700 \mathrm{ppm}, 550 \mathrm{ppm}$, $350 \mathrm{ppm}$ (ambient) in an open top chamber (OTC) and $350 \mathrm{ppm}$ $\mathrm{CO}_{2}$ in the open. Biochemical analysis of the foliage showed that plants grown under the elevated $\mathrm{CO}_{2}$ levels had lower $\mathrm{N}$-content, and higher $\mathrm{C}$-content, $\mathrm{C} / \mathrm{N}$ ratio and polyphenols. The larvae fed on $700 \mathrm{ppm}$ and $550 \mathrm{ppm} \mathrm{CO}_{2}$ foliage exhibited higher consumption. The $700 \mathrm{ppm}$ and $550 \mathrm{ppm} \mathrm{CO}_{2}$ foliage was more digestible with higher values of approximate digestibility. The relative consumption rate of larvae increased, whereas the efficiency parameters, viz. efficiency of conversion of ingested food (ECI), efficiency of conversion of digested food (ECD) and relative growth rate (RGR) decreased in the case of larvae grown on $700 \mathrm{ppm}$ and $550 \mathrm{ppm}$ $\mathrm{CO}_{2}$ foliage. The consumption and weight gain of the larvae were negatively and significantly influenced by the leaf nitrogen, which was found to be the most important factor affecting consumption and growth of larvae.

Likewise in FACE, plants are grown in open field condition in natural settings. Hamilton [28] used FACE technology setting the environment with concentration of oxygen and carbon dioxide assuming the projected condition in middle of $21^{\text {st }}$ century. Soybean was grown under the environment. During early stage, in comparison of ambient field condition, 57\% more damage was seen in the crop primarily by Japanese beetle, potato leafhopper, western corn rootworm and Mexican bean beetle.

\section{Change in precipitation patterns}

Change in amount, intensity, frequency of precipitation are also the indicators of climate change. As observed in most circumstances, frequency of rainfall has declined while increasing the intensity of rainfall. This has prevailed the incidence of droughts and floods. For species that overwinters in soil are directly affected by the overlapping precipitation. Simply put, affecting the diapause, heavy rainfall causing flood and prolonged stagnation of water threatens the survivability of insects. Moreover, eggs and larvae of insects may be washed away by heavy rainfall and flood.

Under heavy showers, small pests such as aphids, jassids, whiteflies, mites, etc. may be washed away [29]. Incidence of Helicoverpa armigera is reported to increase in higher rainfall in November (which is the deviation of normal precipitation pattern). But some species are seen not affected by change in pattern of rainfall. Coccoidea lecanopsis formicarum was seen unaffected by changed rainfall pattern. As well as some species are positively affected by increased rainfall viz. A. lineatus. Incidence of Spodoptera litura is seen in higher in groundnut, cotton, chillies and coriander in enhanced rainfall. Lever [30] analysed the relationship between outbreaks of armyworm, Mythimna separate (Walker) and to a lesser extent Spodoptera mauritia (Boisd.) and rainfall from 1938 to 1965 and observed that outbreaks occurred when rainfall exceeded the average $89 \mathrm{~cm}$.

\section{Effects on pollinators}

Those beneficial insects which in course of life sustaining operations mobilize the pollens from anther to the stigma of same or different flowers can be referred as pollinators. Honey bees, bumble bees, wasps, butterflies, flies etc. are some common pollinators. Approximately 73 percent of the worlds cultivated crops are pollinated by bees, 19 per cent by flies, 6.5 per cent by bats, 5 per cent by wasps, 5 per cent by beetles, 4 per cent by birds, and 4 per cent by butterflies and moths [31]. Insect directed pollination contributes for about one third of global food production. Changing climate has clearly declined the population abundance, geographic range and pollination activities of important pollinator species like bees, moths and butterflies considerably [32]. Temperature and water availability have been found to affect profoundly the critical events like flowering, pollination and fruiting in the life cycle of plants [33]. The quality and the quantity of pollination have multiple implications for food security, species diversity, ecosystem stability and resilience to climate change [32].

Some of the evidences of responses of pests to changing climate are presented below. 


\begin{tabular}{|c|c|c|c|}
\hline Response & Species involved & Details & Source \\
\hline \multirow[t]{2}{*}{ Shifting distribution } & $\begin{array}{l}\text { Penthaleus spp. } \\
\text { (blue Oat mites) }\end{array}$ & $\begin{array}{l}\text { Distributions of the three Penthaleus species in Australia are cor- } \\
\text { related with different climatic variables, suitable climate space } \\
\text { likely to decrease in the future. Cryptic species respond differently. }\end{array}$ & {$[34]$} \\
\hline & $\begin{array}{l}12 \text { pest of fruitfly species } \\
\text { (Tephritidae) }\end{array}$ & $\begin{array}{l}\text { Results from distribution models revealed general patterns of pole } \\
\text { ward movement for the group. For the individual species, distribu- } \\
\text { tion shifts appear to also be eastwards and at finer scales, varying } \\
\text { amounts of species turnover was apparent. These changes in re- } \\
\text { sponse across different scales present regional management chal- } \\
\text { lenges for these species under climate change. }\end{array}$ & [15] \\
\hline Altering Phenology & Cydia pomonella & $\begin{array}{l}\text { Under future conditions of increased temperature in Switzerland, } \\
\text { the risk of an additional third generation will increase from } 0-2 \% \\
\text { to } 100 \% \text { and there will be a two-week shift in earlier overwinter- } \\
\text { ing adult flight. The shiftd in phenology and voltinism will require } \\
\text { change to plant protection strategies. }\end{array}$ & {$[35]$} \\
\hline Adjusting to persist in situ & $\begin{array}{l}\text { Halotydeus destructor } \\
\text { (redlegged earth mite) }\end{array}$ & Greater thermal tolerance in population of Australia than in Africa & {$[36]$} \\
\hline
\end{tabular}

\section{Table 1}

\section{Conclusions}

Climate change has serious impacts on diversity, distribution, incidence, reproduction, growth, development, voltinism and phenology of insect pests. Increasing global temperature, disturbed rainfall patterns, modified gaseous composition etc. can cause increase in population and activity of insect pests. This condition has put forward newer challenges for food security affecting the quality and quantity of agricultural products. However, the climate change acts differently on different species, overall impacts of climate change seems to increase the pest population along with their activity and consequent damage in agriculture. Abundance of such insect pests has already been showing serious impacts on global food production. Pest population is experiencing longitudinal and latitudinal shifts for survival and adaptation. Newer regions where the pest species were not present now are being hub for the pest. Distribution and abundance of insect pests has expanded under the changing environmental parameters. Many species have built resistance and have been able to adapt in the new environment. Increase in agricultural pest is causing incidence of pest outbreaks, pest resurgence, increased adaptability of insects barring the required quality and quantity production of food crops. Under increased population and increased requirement of food, global agriculture (is/going to) face crisis in potential production of agricultural commodities and consequently challenging human food security.

\section{Bibliography}

1. Bale JS., et al. "Herbivory in global climate change research: Direct effects of rising temperature Herbivory in global climate change research: direct effects of rising temperature on insect herbivores". Global Change Biology (2002).

2. CANNON RJ. "The implications of predicted climate change for insect pests in the UK, with emphasis on non-indigenous species". Global Change Biology (1998).

3. Dewar Roderick and Watt AD. "Predicted changes in the synchrony of larval emergence and budburst under climatic warming". Oecologia 89 (1992): 557-559.
4. Harrington R., et al. "Climate change impacts on insect management and conservation in temperate regions: can they be predicted?" Agricultural and Forest Entomology 3 (2001): 233240.

5. Samways M. "Insect Diversity Conservation". Cambridge University Press, Cambridge (2005): 342.

6. Yamamura and Kohji. "A simple method to estimate the potential increase in the number of generations under global warming in temperate zone" (1998).

7. Lewis WJ., et al. "A total system approach to sustainable pest management". (1997): 12243-12248.

8. Gaston Williams. Biodiversity - latitudinal gradients (1996).

9. Andrew Nigel R and Hughes Lesley. Diversity and assemblage structure of phytophagous Hemiptera along a latitudinal gradient: predicting the potential impacts of climate change". (2005): 249-262.

10. AWMACK C., et al. "Host Plant effects on the performance of the aphid Aulacorthum solani (Kalt.) (Homoptera: Aphididae) at ambient and elevated CO2". Global Change Biology 3 (2003): 545-549.

11. Kremen C., et al. "Terrestrial Arthropod Assemblages: Their Use in Conservation Planning Terrestrial Arthropod Assemblages: Their Use in Conservation Planning". Conservation Bi$\operatorname{ology}(1993)$.

12. Kannan., et al. "Effects of climate change on global biodiversity: a review of key literature". 50 (2009): 31-39.

13. Thomas C., et al. "Extinction risk from climate change Extinction risk from climate change". Nature (2014).

14. Bebber DP., et al. "Crop pests and pathogens move polewards in a warming world". Nature Climate change 3 (2013): 1-4.

15. Hill BCT. "Predicted decrease in global climate suitability masks regional complexity of invasive fruit fly species response to climate change". Biological Invasion (2016). 
16. Carroll AL., et al. "Effects of Climate Change on Range Expansion by the Mountain Pine Beetle in British Columbia" (2004): 223-232.

17. Logan JA., et al. "Assessing the impacts of global warming on forest pest dynamics" (2000): 130-137.

18. Menéndez R., et al. "Direct and indirect effects of climate and habitat factors on butterfly diversity". Ecology 88 (2007): 605611.

19. Gordo Sanz. "Phenology and climate change: A long-term study in a Mediterranean locality”. Oecologia 146 (2005): 484-495.

20. Pathak H., et al. Climate Change Impact, Adaptation and Mitigation in Agriculture: Methodology for Editors (2012).

21. Roy DB and Sparks Tim. "Phenology of British butterflies and climate change". Global Change Biology 6 (2000): 407-416.

22. Jazeera A. (n.d.). earthrise - Food: Farming for the Future earthrise.

23. Pareek Abhisek BM. Impact of Climate Change on Insect Pests and Their Management Strategies (2016).

24. Petzoldt Curtis and Seaman Abby. "Climate Change Effects on Insects and Pathogens" (2005).

25. Coviella CE and Trumble T. "Effects of elevated atmospheric carbon dioxide on insect plant interaction". Conservation Biology 13 (1999).

26. Williams R., et al. "Effects of elevated CO2 and temperaturegrown red and sugar maple on gypsy moth performance". Global Change Biology (1994): 685-695.

27. Rao GR. "Trends in rainfall and temperature in rainfed India in previous century". In P. Aggrawal (Ed.), Global climate change and Indian Agriculture case studies from ICAR network project (pp. 71-73). New Delhi: ICAR Publication (2009).

28. Hamilton J. "Effects of climate change on international tourism". Climate Research 29 (2005): 245-254.

29. Pathak H., et al. Climate Change Impact, Adaptation and Mitigation in Agricultur: Methodology for Editors (2012).

30. Lever R. “Do armyworm follow the rain?” (1969): 351-352.

31. Abrol DP. "Pollination - Basic Concepts”. In D. P. Abrol, Pollination Biology (2009).

32. FAO. "Rapid Assessment of Pollinators Status" (2008).

33. Cleland CI. "Shifting plant phenology in response to global change". Trends in Ecology and Evolution (2007): 357-365.

34. Hill MP. "A predictive framework to assess response of invasive invertebrates to climate change: pest mite species of Australian grains" (2012).

35. Stoeckli S., et al. "Impact of Climate Change on Voltinism and Prospective Diapause Induction of a Global Pest Insect - Cydia pomonella (L.)”. PLOS ONE 7 (2012).
36. Hill. "A predicted niche shift corresponds with increased thermal resistance in an invasive mite, Halotydeus destructor". Global Ecology and Biogeography (2013).

\section{Volume 3 Issue 12 December 2019}

(c) All rights are reserved by Saroj Shrestha. 